\title{
Omental Metastasis from ALK-positive Lung Cancer - A Case Report
}

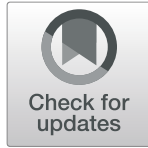

Taha Khalid*iD, Brendan Phelan and Ala Yousif

\begin{abstract}
Background: Non-small cell lung cancer (NSCLC) is the leading cause of cancer-related deaths worldwide. In Ireland alone, there are over 2500 new cases of lung cancer diagnosed each year. It ranks fourth among the most common cancers and causes $21 \%$ of all cancer-related deaths.

Lung cancers usually metastasize to the liver, brain, bone, and adrenal glands-rarely affecting the abdomen. To our knowledge, there are 8 previous studies in the literature to date which involve omental metastasis from NSCLC.

Case presentation: A 73-year-old lady presented with a history of productive cough for 18 months. A chest X-ray showed a suspicious $6 \mathrm{~cm}$ mass in the right lower zone. She went on to have an endobronchial biopsy which confirmed a moderately differentiated adenocarcinoma of the lung which was ALK positive. She went on to have staging PET and CT scans and was staged as CT3N2M0. She was not a suitable candidate for surgery so she had radical chemo-radiotherapy with 4 cycles of cisplatin pemetrexed followed by radical dose sequential radiotherapy. Post treatment $\mathrm{CT}$ showed the tumor to be more spiculated in appearance. She was ineligible for Durvalumab maintenance therapy due to the extensive pneumonitis following her radiotherapy which required a prolonged course of steroids. Interval scans every 3 months did not show any progression of disease.

She presented to the hospital 13 months post her diagnosis with progressive abdominal swelling. Restaging CT scans showed extensive omental infiltration, the presence of multiple peritoneal nodules, and progression of her pulmonary disease with new brain metastasis. Cytological analysis of the ascitic fluid confirmed metastasis followed by omental biopsy which confirmed metastatic ALK-positive NSCLC. She went on to have targeted treatment with alectinib. She tolerated the treatment well. Restaging scans done 3 months later showed good partial response to therapy.

Conclusion: In conclusion, ALK-positive NSCLC with metastasis to the omentum is very rare. However, in patients with atypical symptoms like ascites, the possibility of a metastasis must be considered and repeat biopsy is always recommended. A targeted therapy in the selected patients has shown a more durable response than chemotherapy.
\end{abstract}

\section{Background}

Non-small cell lung cancer (NSCLC) is the leading cause of cancer-related deaths worldwide. In Ireland alone, there are over 2500 new cases of lung cancer diagnosed each year. It ranks fourth among the most common cancers and causes $21 \%$ of all cancer-related deaths [1].

Lung cancers usually metastasize to the liver, brain, bone, and adrenal glands-rarely affecting the abdomen. To our knowledge, there are 8 previous studies in the literature to date which involve omental metastasis from NSCLC [2-9].

\footnotetext{
*Correspondence: tahakhalid@outlook.ie

Department of Medical Oncology, Sligo University Hospital, Sligo, Ireland
}

\section{Case presentation}

A 73-year-old lady presented with a history of worsening productive cough for 18 months. She did not initially seek any medical attention as she did not like going to her family doctor (GP). However, when the cough started interfering with her activities of daily living, she went to her GP. Physical exam by the GP revealed decreased air entry in the right base but no other significant findings. A chest X-ray showed a suspicious $6-\mathrm{cm}$ mass in the right lower zone (Fig. 1).

She was immediately referred to the rapid lung access clinic and went on to have an endobronchial biopsy which confirmed a moderately differentiated adenocarcinoma of
SpringerOpen

(c) The Author(s). 2020 Open Access This article is licensed under a Creative Commons Attribution 4.0 International License, which permits use, sharing, adaptation, distribution and reproduction in any medium or format, as long as you give appropriate credit to the original author(s) and the source, provide a link to the Creative Commons licence, and indicate if changes were made. The images or other third party material in this article are included in the article's Creative Commons licence, unless indicated otherwise in a credit line to the material. If material is not included in the article's Creative Commons licence and your intended use is not permitted by statutory regulation or exceeds the permitted use, you will need to obtain permission directly from the copyright holder. To view a copy of this licence, visit http://creativecommons.org/licenses/by/4.0/. 


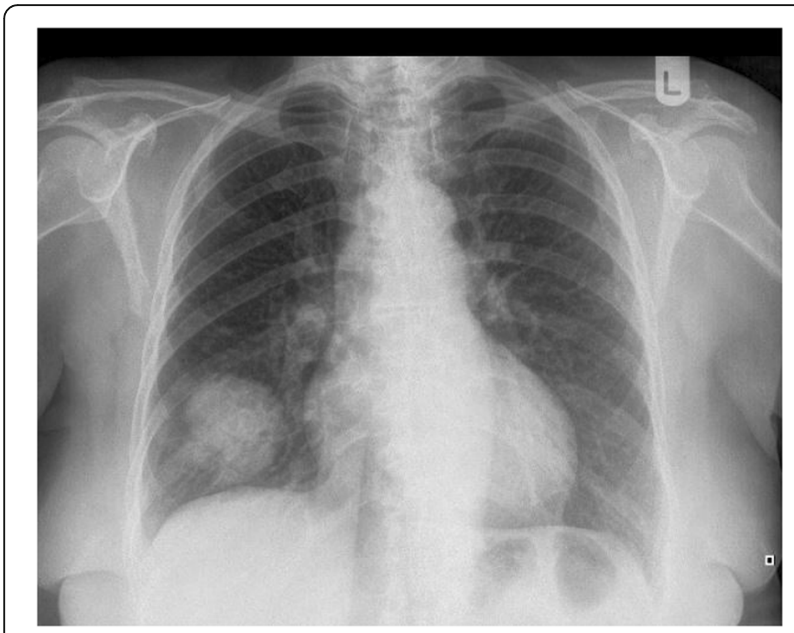

Fig. 1 Initial chest X-ray on presentation

the lung which was ALK-positive. She went on to have staging PET and CT scans and was staged as CT3N2M0. She was not a suitable candidate for surgery so she had radical chemo-radiotherapy with 4 cycles of cisplatin pemetrexed followed by radical dose sequential radiotherapy (55 Gy/20 F). Post treatment CT showed the primary tumor to be more spiculated in appearance. She was deemed ineligible for durvalumab maintenance therapy due to the extensive pneumonitis following her radiotherapy which required a long course of steroids. Interval scans every 3 months did not show any progression of disease.

She presented to the hospital 13 months post her diagnosis with progressive abdominal swelling. A restaging CT scan showed restaging CT scans showed extensive omental infiltration, the presence of multiple peritoneal nodules and progression of her pulmonary disease with new brain metastasis (Figs. 2, 3 and 4). Cytological

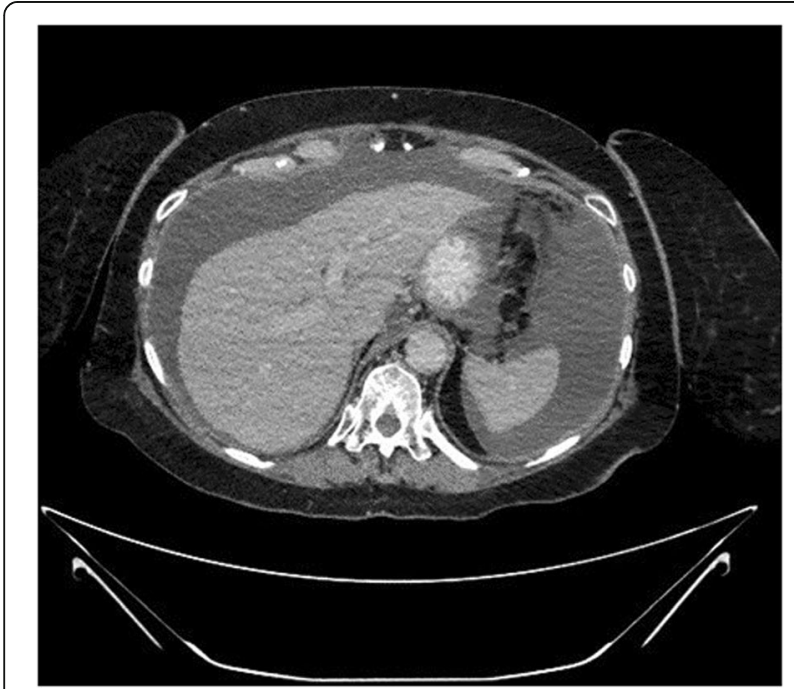

Fig. 2 Extensive ascities

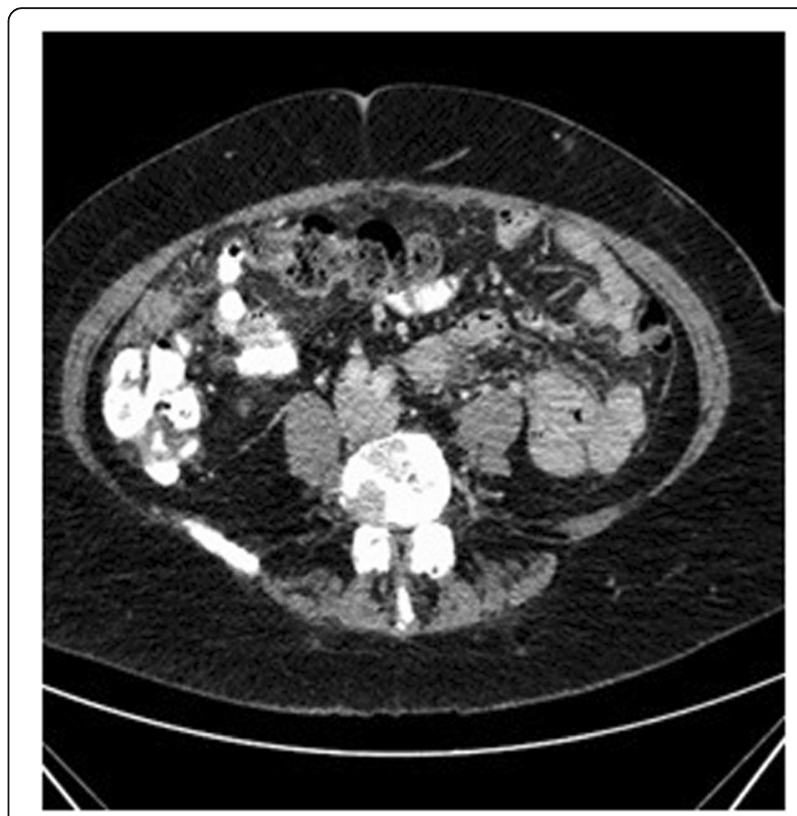

Fig. 3 Omental nodularity

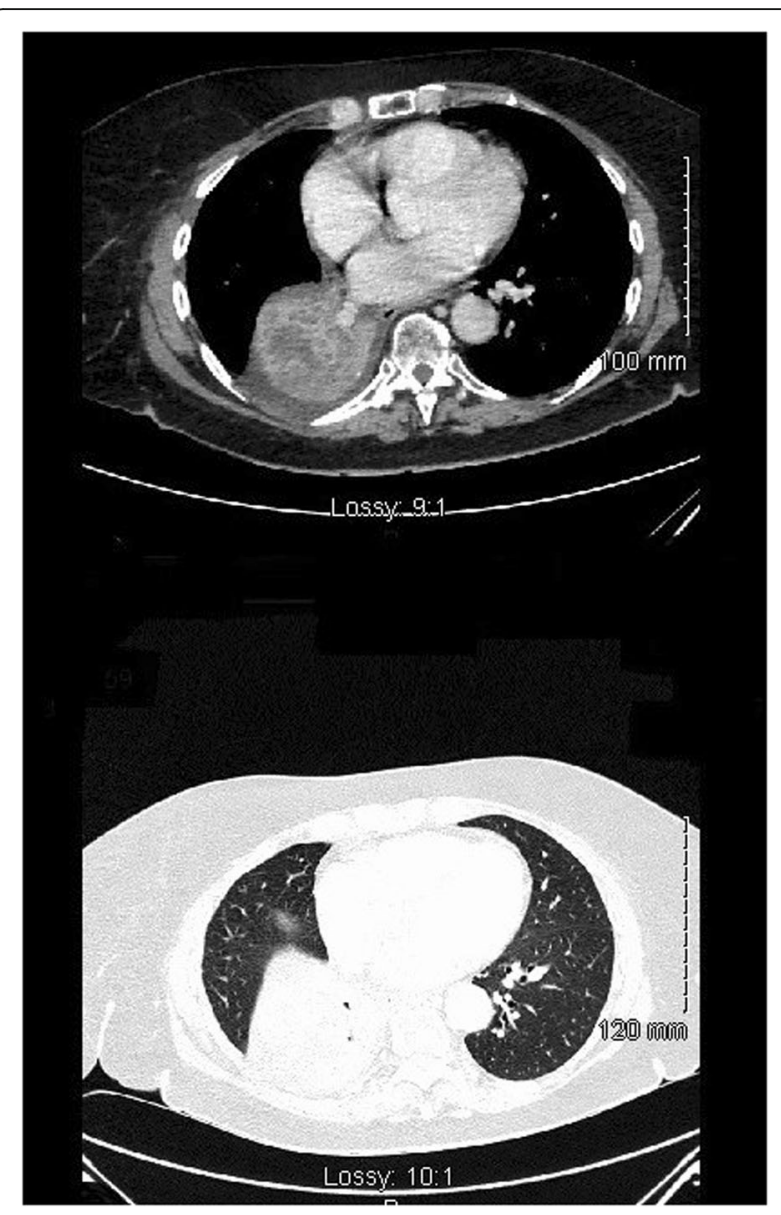

Fig. 4. CT Thorax prior to initiation of alectinib 
analysis of the ascitic fluid and omental biopsy confirmed metastatic ALK-positive NSCLC.

Targeted therapy in the form of the tablet alectinib was commenced at a dose of $600 \mathrm{mg}$ twice a day with a view to continue indefinitely until progression of disease or unacceptable toxicity. The reason for choosing alectinib over the more widely available crizotinib was that two studies have shown that alectinib has better CNS penetrance compared to crizotnib [10]. She tolerated the treatment well. Restaging scans done 3 months later showed good partial response to therapy (Fig. 5).

There was a decrease of the primary lung leision from 5 to $4 \mathrm{~cm}$ with no new lung leisions. The previous left paratracheal lymph node had also significantly decreased in size. There was a new left pleural effussion, but the patient was asymptomatic. The omental and disease was stable with no further progression in the brain metastasis.

\section{Discussion}

NSCLCs commonly metastasize to the brain, bone, and liver. They usually metastasize via the lymphatic system; however, they can spread hematologically. They very

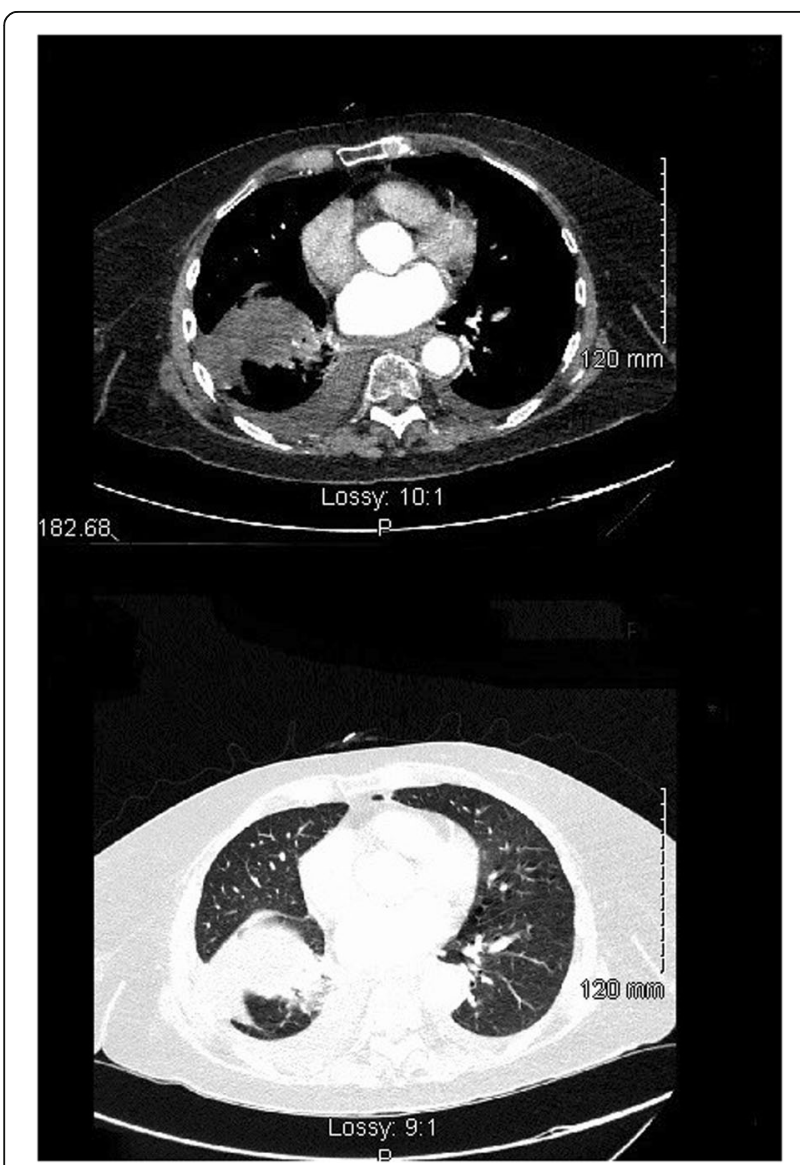

Fig. 5 CT Thorax 3 months post treatment with alectinib rarely involve the abdomen, and to the best of our knowledge, only 8 studies have reported cases of omental metastases from primary lung cancers in the literature [2-9].

ALK is a tyrosine kinase receptor that is rearranged in about 5\% of NSCLCs [11]. Rearrangement results in dysregulation and inappropriate signaling through the ALK domain. It has been reported to be more common in light or never smokers and among people with adenocarcinoma histology without other genetic mutations for example EGFR which accurately describes the patient in this case. Gene mutations involving ALK are associated with responsiveness to ALK tyrosine kinase inhibitors such as crizotinib and alectinib. In this case, our patient showed good response to alectinib therapy.

ALK inhibitors like crizotinib and alectinib are not without their side effects. In a recent meta-analysis, it was found that visual disturbances were the most common side effects in patients on crizotinib while mild GI disturbances (nausea and diarrhea) were frequently encountered by patients on second generation ALK inhibitors.

Prior to the discovery of targetable mutations like ALK, EGFR, and ROS 1 patients with NSCLC were treated with standard platinum-based chemotherapy. Now with potential targetable mutations and availability of drugs like alectinib, we can have a more durable and well-tolerated response than standard chemotherapy in patients who carry these mutations.

\section{Conclusion}

In conclusion, ALK-positive NSCLC with metastasis to the omentum is very rare. However, in patients with atypical symptoms like ascites, the possibility of a metastasis must be considered and repeat biopsy is always recommended. Targeted therapy in selected patients has shown a more durable response than chemotherapy.

\section{Abbreviations \\ ALK: Anaplastic lymphoma kinase; CT: Computed tomography; \\ EGFR: Epidermal growth factor receptor; F: Fractions; Gy: Gray; NSCLC: Non- small cell lung cancer; PET: Positron emission tomography; ROS 1: Gene encoding proto-oncogene tyrosine-protein kinase ROS enzyme}

\section{Acknowledgements}

AY was our consultant as well as mentor in this project and guided us extensively throughout this process. The authors have read and approved the manuscript.

\section{Authors' contributions \\ TK contributed to the conception and design of the work as well as data interpretation. BP contributed to the analysis and interpretation of the data as well as drafting and substantively drafting the case report. The author(s) read and approved the final manuscript.}

\section{Funding}

No funding was required for this case report.

Availability of data and materials

Data will not be shared due to GDPR regulations as it is stored in the patient's confidential records. 


\section{Ethics approval and consent to participate}

The patient gave consent for her details to be included in the publication, and she has since passed away and has no next of kin. Institutional ethical approval was also undertaken for this study.

\section{Consent for publication}

Written approval is taken from the patient for writing up and publication of this article.

\section{Competing interests}

The authors declare that they have no competing interests.

Received: 16 June 2020 Accepted: 13 July 2020

Published online: 17 November 2020

\section{References}

1. Ireland NCR (2018) Cancer factsheet-lung, Ireland

2. Garavello A, Fransvea P, Rossi S, Giacovazzo F, Marino V (2018) Bowel perforation secondary to metastatic lung cancer: report of two cases with literature review. Int J Surg Case Rep 51:331-334. https://doi.org/10.1016/j. ijscr.2018.07.039

3. Matsuda Y, Fujiwara Y, Kishi K, Okami J, Sugimura K, Motoori M, Miyoshi N, Noura S, Ohue M, Gotoh K, Marubashi S, Akita H, Takahashi H, Sakon M, Yano M (2016) Surgical resection of solitary omental metastasis from nonsmall cell lung cancer: report of three cases. Oncol Lett 11(1):563-567. https://doi.org/10.3892/ol.2015.3942 Epub 2015 Nov 18. PMID: 26870248; PMCID: PMC4727180

4. Sakurai T, Nakamura T, Yoshimasu T, Naito Y, Matsuyama K (2011) Oura S. A case of strangulation ileus due to intraabdominal metastases of lung cancer demanded an emergency operation, Nihon Rinsho Geka Gakkai Zasshi (Journal Japan Surg Assoc)

5. Chantharasamee J, Poungvarin N, Danchaivijitr P, Techawatanawanna S (2019) Clinical outcome of treatment of metastatic non-small cell lung cancer in patients harboring uncommon EGFR mutation. BMC Cancer 19(1): 701. Published 2019 Jul 17. https://doi.org/10.1186/s12885-019-5913

6. Ioannidis O, Iordanidis F, Paraskevas G, Chatzopoulos S, Kotronis A, Papadimitriou N, Konstantara A, Makrantonakis A, Kakoutis E (2012) Omental metastases from primary lung adenocarcinoma. Rev Investig Clin 64:308-310

7. Oshika Y, Hashimoto H (2008) Two cases of non-small cell lung cancer with metastasis to the omentum. Haigan. 48:118-122

8. Masai Y, Miyahara T, Kaihara S, Hosotani R, Miki A, Okada N (2011) A case report of omental metastasis of pleomorphic carcinoma of the lung which regrowed surprisingly fast after surgical resection. Japanese J Gastroenterol Surg

9. Guérin E, Gilbert O, Dequanter D (2009) Acute abdomen: a rare presentation of lung cancer metastasis. Case Rep Med 2009(2009):903897 Available from: https://www.ncbi.nlm.nih.gov/pubmed/19841757

10. Gadgeel SM, Shaw AT, Govindan R et al (2016) Pooled analysis of CNS response to alectinib in two studies of pretreated patients with ALK-positive non-small-cell lung cancer [published correction appears in J Clin Oncol. 2017 May 10;35(14):1631]. J Clin Oncol 34(34):4079-4085. https://doi.org/10. 1200/JCO.2016.68.4639

11. Zhang NN, Liu YT, Ma L, Wang L, Hao XZ, Yuan Z, Lin DM, Li D, Zhou YJ, Lin $H$, Han XH, Sun Y, Shi Y (2014) The molecular detection and clinical significance of ALK rearrangement in selected advanced non-small cell lung cancer: ALK expression provides insights into ALK targeted therapy. PLoS One 9(1):e84501. https://doi.org/10.1371/journal.pone.0084501 PMID: 24404167; PMCID: PMC3880316

\section{Publisher's Note}

Springer Nature remains neutral with regard to jurisdictional claims in published maps and institutional affiliations. 